\title{
EVALUASI PROGRAM SANITASI TOTAL BERBASIS MASYARAKAT PILAR STOP BABS DI PUKSESMAS KABUPATEN PROBOLINGGO
}

\author{
EVALUATION PROGRAM OF COMMUNITY LED TOTAL SANITATION PILLAR STOP BABS IN PUBLIC \\ HEALTH CENTER PROBOLINGGO DISTRICT
}

Farouk IImid Davik

Fakultas Kesehatan Masyarakat, Universitas Airlangga, Surabaya

E-mail: davik.fkmua@gmail.com

\begin{abstract}
Community Led Total Sanitation (CLTS) is the program of government to reduce the incidence of diarrhea and improve public hygiene behavior through otriggers approach. CLTS consists of five pillars with its main focus is pillar Stop BABS. Goal of this research is to evaluate the implementation of program CLTS (Stop BABS) with a systems approach which conducted of input, process and output in Public Health Center (PHC) in Probolinggo district. This is an observational research using with cross sectional design. This research analyzes used descriptive. Population and sample of this research is 26 PHC sanitation workers in Probolinggo. Results of this research showed the planning process was still bad, the implementation of the program was good, recording and reporting was also good, and the process of mentoring and advocacy program was still bad. Inhibiting factor of CLTS program is budget and geographical environment. The implementation of CLTS program (Stop BABS) as a whole in PHC Probolinggo district still not succeeded. Suggestion for PHC sanitation workers is making plan of action CLTS program, establishing village-level facilitators CLTS, implementing mentoring and advocacy as well as increase cooperation across sectors and programs.
\end{abstract}

Keywords: CLTS, Evaluation, Management system

\section{PENDAHULUAN}

Tujuan adanya Peraturan Menteri Kesehatan (Permenkes) RI nomor 03 tahun 2014 tentang Sanitasi Total Berbasis Masyarakat (STBM adalah untuk menurunkan angka kejadian diare dan meningkatkan higienitas dan kualitas kehidupan masyarakat Indonesia. Program STBM merupakan pendekatan untuk mengubah perilaku higienis dan saniter melalui pemberdayaan masyarakat dengan cara pemicuan. Pelaksanaan program STBM yang menitiberatkan pada kesadaran dan partisipasi masyarakat akan pentingnya buang air besar di Jamban sehat menjadi suatu tantangan bagi petugas sanitasi Puskesmas.

Berdasarkan hasil Riskesdas tahun 2013 menunjukkan bahwa Kabupaten Probolinggo merupakan salah satu kabupaten tertinggi di Jawa Timur dengan $36,8 \%$ rumah tangga yang tidak memiliki fasilitas buang air besar (BAB). Jumlah desa di kabupaten Probolinggo yang telah terverifikasi Open Defecation Free (ODF) hanya 16 desa dari total 127 desa yang telah dilakukan kegiatan pemicuan. ODF merupakan suatu kondisi dimana individu dalam komunitas tidak lagi melakukan perilaku buang air besar sembarangan (BABS) yang berpotensi mengurangi penyebaran penyakit. Kegiatan pemicuan yang terus menerus dilakukan mulai tahun 2013 hingga tahun 2015 memiliki pengaruh dalam menurunkan kasus diare di Kabupaten Probolinggo. Hasil monitoring dan evaluasi program STBM Dinas Kesehatan Kabupaten Probolinggo tahun 2014 - 2015 menunjukkan terdapat 26 Puskesmas yang belum mencapai target akses sanitasi jamban sehat yaitu $75 \%$. Belum tercapainya target STBM mengindikasikan bahwa kinerja petugas sanitasi 
Puskesmas dan partisipasi masyarakat dalam pelaksanaan program STBM pilar Stop BABS masih belum optimal. Sehingga, Perlu adanya langkah evaluasi terhadap program STBM pilar Stop BABS untuk mengetahui apa yang menjadi penyebab dan faktor yang menghambat proses pelaksanaan program STBM di Puskesmas Kabupaten Probolinggo.

Penelitian ini bertujuan untuk mengevaluasi program STBM pilar Stop BABS di Puskesmas Kabupaten Probolinggo. Manfaat dari penelitian ini dapat menjadi masukan guna meningkatkan proses perencanaan dan evaluasi program STBM di Puskesmas Kabupaten Probolinggo.

\section{PUSTAKA}

\section{Evaluasi Program}

Menurut Stufflebeam \& Shinkfield (2007) evaluasi program sebagai upaya dalam mengumpulkan informasi tentang bekerjanya program pemerintah sebagai alternatif yang tepat dalam mengambil sebuah keputusan. Tujuan evaluasi program sebagai alat untuk memperbaiki perencanaan dan pelaksanaan program yang akan datang. Evaluasi program juga untuk mengetahui tingkat keterlaksanaan suatu kebijakan secara cermat dengan cara mengetahui efektivitas tiap komponen. Evaluasi terhadap proses dititiberatkan pada pelaksanaan program, apakah sesuai dengan rencana yang telah ditetapkan atau tidak. Penilain tersebut juga bertujuan untuk mengetahui apakah metode yang dipilih sudah efektif atau tidak efektif.

Sanitasi Total Berbasis Masyarakat (STBM)
Menurut Permenkes RI Nomor 03 tahun 2014

tentang STBM adalah pendekatan untuk mengubah perilaku higienis dan saniter melalui pemberdayaan masyarakat dengan cara pemicuan. Pilar STBM merupakan acuan dalam penyelenggaraan STBM yang terdiri dari pilar stop BABS, cuci tangan pakai sabun, pengelolaan air minum dan makanan rumah tangga, pengamanan sampah rumah tangga, dan pengamanan limbah cair rumah tangga. Stop BABS adalah kondisi ketika setiap individu dalam suatu komunitas tidak lagi melakukan perilaku $B A B$ yang berpotensi dalam penyebaran penyakit lingkungan.

Berdasarkan road map STBM di Indonesia tahun 2013-2015, Indikator dari pilar pertama (Stop BABS) adalah meningkatnya persentase penduduk yang menggunakan akses jamban sehat yaitu $75 \%$ dan persentase penduduk yang Stop BABS sebesar $100 \%$. Standar dari pelaksanaan pemicuan pilar Stop BABS meliputi kegiatan perencanaan, pelaksanaan, pemantauan dan evaluasi, pencatatan dan pelaporan, pendampingan dan advokasi. Perencanaan meliputi identifikasi masalah dan analisis situasi, perencanaan waktu, tempat dan sasaran kegiatan, penyiapan fasilitator desa, advokasi kepada tokoh masyarakat.

Penyelenggaraan program STBM dilakukan dengan cara pemicuan oleh tenaga kesehatan, kader, relawan atau masyarakat yang telah berhasil mengembangkan program STBM. Kegiatan pemicuan diarahkan untuk memberikan kemampuan dalam merencanakan perubahan perilaku, memantau atau terjadinya perubahan perilaku serta mengevaluasi hasil perubahan perilaku dari masyarakat. 
Kar \& Chambers (2008) menyatakan bahwa strategi pelaksanaan program STBM meliputi tiga komponen yang saling mendukung antara satu dengan yang lain. Strategi tersebut meliputi penciptaan lingkungan yang kondusif, peningkatan kebutuhan sanitasi, dan peningkatan penyediaan akses sanitasi. Apabila salah satu dari komponen STBM tersebut tidak ada, maka proses pencapaian 5 pilar STBM tidak akan berhasil secara maksimal.

Komponen penciptaan lingkungan yang kondusif mencangkup advokasi kepada pemerintah, dan pemangku kepentingan untuk mengembangkan komitmen untuk melembagakan program pembangunan sanitasi pedesaan. Komponen peningkatan kebutuhan sanitasi merupakan sanitasi untuk mendapatkan perubahan perilaku higines dan saniter. Komponen peningkatan penyediaan akses sanitasi secara khusus diprioritaskan untuk meningkatan dan mengembangkan percepatan penyediaan akses sanitasi yang layak.

\section{METODE}

Penelitian ini merupakan jenis penelitian observasional deskriptif karena tanpa melakukan intervensi apapun pada populasi dan bertujuan untuk mendeskripsikan hasil evaluasi program STBM pilar Stop BABS di Kabupaten Probolinggo. Rancang bangun penelitian dengan studi crossectional yaitu data yang dikumpulkan dalam satu waktu tertentu secara bersamaan. Waktu penelitian dan pengumpulan data serta analisis data dilaksanakan mulai 14 April - 30 Mei 2016. Populasi dalam penelitian ini adalah seluruh petugas sanitasi Puskesmas di Kabupaten Probolinggo. Petugas sanitasi Puskesmas merupakan salah satu fasilitator STBM tingkat kecamatan dan sebagai informan dalam penelitian ini dengan jumlah 26 responden.

Data primer diperoleh menggunakan wawancara dengan kuesioner sedangkan data sekunder melalui hasil observasi check list data tiap Puskesmas dan Dinas Kesehatan Kabupaten Probolinggo. Seluruh data yang telah dikumpulan dianalisis secara deskriptif untuk menggambarkan proses pelaksanaan program STBM pilar Stop BABS secara sistematis berdasarkan fakta atau kondisi lapangan di Puskesmas. Kategori hasil penelitian dari penentuan skoring jawaban (ya,tidak) berdasarkan skala gutmans. Kegiatan program dikatakan baik jika $\geq 80 \%$ responden melakukan langkah program STBM sesuai dengan pedoman dan setelah di cross check keberadaan dokumen ada dan benar. Sedangkan kegiatan dikatakan buruk jika $\leq 79$ responden tidak melakukan langkah program STBM dan setelah di cross check keberadaan dokumen tidak ada.

Instrumen yang digunakan dalam penelitian ini adalah kuesioner berisi penilaian responden terhadap variabel penelitian. Kuesioner untuk pengumpulan data terlebih dahulu diuji validitas dan uji reliabilitas sebelum dibagikan kepada responden.

\section{HASIL DAN PEMBAHASAN}

Tahapan proses program STBM pilar Stop BABS meliputi perencanaan, pelaksanaan, pemantauan dan evaluasi, pencatatan dan pelaporan, pendampingan dan advokasi. Hasil penelitian tentang pendapat responden mengenai 
proses program STBM dan hasil evaluasi terhadap

dokumen perencanaan adalah sebagai berikut.

Tabel 1. Distribusi Evaluasi Perencanaan Program STBM Pilar Stop BABS di Puskesmas Kabupaten Probolinggo Tahun 2015-2016

\begin{tabular}{|c|c|c|c|c|c|c|c|}
\hline \multirow{3}{*}{ Variabel Perencenaan } & \multicolumn{4}{|c|}{ Pendapat Responden } & \multicolumn{2}{|c|}{ Keadaan Dokumen } & \multirow{3}{*}{ Kategori } \\
\hline & \multicolumn{2}{|c|}{ Melakukan } & \multicolumn{2}{|c|}{$\begin{array}{c}\text { Tidak } \\
\text { Melakukan }\end{array}$} & \multirow[t]{2}{*}{ Ada } & \multirow[t]{2}{*}{ Tidak ada } & \\
\hline & $\mathbf{N}$ & $\%$ & $\mathbf{N}$ & $\%$ & & & \\
\hline Analisis situasi, identifikasi masalah & 17 & $65 \%$ & 9 & $35 \%$ & & $\sqrt{ }$ & Buruk \\
\hline $\begin{array}{l}\text { Perencanaan waktu, tempat, dan } \\
\text { sasaran pemicuan }\end{array}$ & 26 & $100 \%$ & 0 & $0 \%$ & $\sqrt{ }$ & & Baik \\
\hline Membentuk fasilitator tingkat desa & 2 & $8 \%$ & 24 & $92 \%$ & & $\sqrt{ }$ & Buruk \\
\hline Advokasi kepada tokoh masyarakat & 26 & $100 \%$ & 0 & $0 \%$ & & $\sqrt{ }$ & Baik \\
\hline Membentuk forum diskusi & 15 & $58 \%$ & 11 & $42 \%$ & & $\sqrt{ }$ & Buruk \\
\hline
\end{tabular}

\section{Perencanaan}

Berdasarkan tabel 1 diketahui bahwa proses perencanaan program STBM pilar Stop BABS di Kabupaten Probolinggo masih dalam kategori buruk. Hanya $65 \%$ petugas sanitasi yang melakukan analisis situasi dan identifikasi masalah sedangkan $92 \%$ petugas belum membentuk fasilitator STBM tingkat desa serta dokumen perencanaan tidak dibuat oleh Petugas Puskesmas. Hal ini tidak sesuai dengan Pedoman Pelaksanaan Pemicuan Program STBM tahun 2008 yang menjelaskan perlunya dilakukan analisis situasi untuk menggambarkan kondisi sanitasi masyarakat terlebih dahulu walaupun keadaan dokumen hanya sebagai bukti terlaksananya suatu kegiatan.

Trihono (2005) menjelaskan bahwa analisis situasi adalah telaah dari keadaan yang ada saat sekarang dan merupakan awal dari penerapan manajemen program kesehatan. Sedangkan identifikasi masalah ditentukan dari hasil daftar masalah yang ada. Masalah yang telah terdaftar kemudian dikelompokkan menurut konsep manajemen dan konsep sistem. Kegiatan analisis situasi masalah merupakan hal yang penting untuk keberlangsungan keberhasilan perencanaan program STBM di Puskesmas Kabupaten Probolinggo. Petugas sanitasi Puskesmas beranggapan bahwa tanpa melakukan analisis situasi dan identifikasi masalah tidak berpengaruh dalam pelaksanaan pemicuan. Karena proses perencanaan program STBM dilakukan secara topdown oleh Dinas Kesehatan, sehingga petugas sanitasi Puskesmas hanya mengikuti instruksi dari Dinas Kesehatan.

$$
\text { Petugas sanitasi Puskesmas belum }
$$
seluruhnya membentuk fasilitator STBM tingkat desa, hal ini dapat menjadi kendala dalam keberhasilan program STM. Zasrtow (2008) menyatakan bahwa peran fasilitator dalam program pemberdayaan sangatlah penting sebagai enable, dimana seseorang dapat membantu masyarakat agar mau mengungkapkan dan menjelaskan sejauh mana masalah yang sedang dihadapi masyarakat. Mayoritas masyarakat lebih memilih untuk bekerja dan mengerjakan aktivitas lainnya dibandingkan menjadi seorang kader atau fasilitator STBM. Padahal pembentukan fasilitator STBM tingkat desa 
penting untuk keberlangsungan pelaksanaan

pemicuan dan pasca pemicuan program STBM.

Tabel 2. Distribusi Proses Pelaksanaan Program STBM pilar Stop BABS di Puskesmas Kabupaten Probolinggo Tahun 2015-2016

\begin{tabular}{|c|c|c|c|c|c|c|c|}
\hline \multirow[t]{3}{*}{ Variabel Pelaksanaan } & \multicolumn{4}{|c|}{ Pendapat Responden } & \multicolumn{2}{|c|}{$\begin{array}{l}\text { Keadaan } \\
\text { Dokumen }\end{array}$} & \multirow[t]{3}{*}{ Kategori } \\
\hline & \multicolumn{2}{|c|}{ Melakukan } & \multicolumn{2}{|c|}{ Tidak Melakukan } & \multirow[t]{2}{*}{ Ada } & \multirow{2}{*}{$\begin{array}{c}\text { Tidak } \\
\text { ada }\end{array}$} & \\
\hline & $\mathbf{N}$ & $\%$ & $\mathbf{N}$ & $\%$ & & & \\
\hline Pendataan sasaran pemicuan & 26 & $100 \%$ & 0 & $0 \%$ & $\sqrt{ }$ & & Baik \\
\hline Pengantar pertemuan & 11 & $42 \%$ & 15 & $58 \%$ & $\sqrt{ }$ & & Buruk \\
\hline Pencairan suasana & 11 & $42 \%$ & 15 & $58 \%$ & $\sqrt{ }$ & & Buruk \\
\hline Menjelaskan istilah tentang STBM & 11 & $42 \%$ & 15 & $58 \%$ & $\sqrt{ }$ & & Buruk \\
\hline Pemetaan sanitasi masyarakat & 26 & $100 \%$ & 0 & $0 \%$ & $\sqrt{ }$ & & Baik \\
\hline Penelusuran wilayah & 26 & $100 \%$ & 0 & $0 \%$ & $\sqrt{ }$ & & Baik \\
\hline Diskusi dengan masyarakat & 26 & $100 \%$ & 0 & $0 \%$ & $\sqrt{ }$ & & Baik \\
\hline Membentuk forum komite sanitasi & 26 & $100 \%$ & 0 & $0 \%$ & $\sqrt{ }$ & & Baik \\
\hline $\begin{array}{l}\text { Menyusun rencana program } \\
\text { pembangunan jamban sehat }\end{array}$ & 26 & $100 \%$ & 0 & $0 \%$ & $\sqrt{ }$ & & Baik \\
\hline $\begin{array}{l}\text { Kerjasama dengan lintas sektor dan } \\
\text { lintas program }\end{array}$ & 15 & $58 \%$ & 11 & $42 \%$ & & $\sqrt{ }$ & Buruk \\
\hline
\end{tabular}

\section{Pelaksanaan}

Tabel 2 diketahui bahwa proses pelaksanaan program STBM pilar Stop BABS di Puskesmas Kabupaten Probolinggo sudah dalam kategori baik. Mayoritas petugas sanitasi telah melakukan pendataan sasaran, pemetaan wilayah, penelusuran wilayah, pembentukan komite sanitasi, serta diskusi dan menyusun rencana pembangunan jamban sehat bersama masyarakat. Artinya, proses pelaksanaan pemicuan oleh petugas sanitasi Puskesmas sudah sesuai dengan pedoman pelaksanaan program STBM. Hanya saja masih terdapat petugas sanitasi Puskesmas (58\%) yang tidak melakukan pemicuan secara langsung, hal ini dikarenakan mereka meminta bantuan Sanitarian dari Puskesmas lain untuk membantu pemicuan di wilayah kerjanya. Keadaan dokumen tidak memiliki pengaruh dalam hasil perhitungan persentase, karena keadaan dokumen hanya sebagai bukti adanya dokumen keberlangsungan pelaksanaan pemicuan program.
Dalam pelaksanaannya, pemicuan dilakukan minimal 3 kali dalam 1 tahun untuk periode tertentu dengan lama waktu sekitar 1-3 jam. Tujuannya untuk menghindari informasi yang terlalu banyak dan dapat membuat bingung masyarakat. Pemicuan dilakukan berulang kali sampai ada masyarakat yang terpicu. Orang yang terpicu ialah orang yang tergerak dengan spontan dan menyatakan untuk merubah perilaku.

Sholikhah (2012) menjelaskan bahwa terdapat hubungan antara pelaksanaan program STBM pilar stop BABS dengan perubahan perilaku masyarakat dalam BABS. Karena pelaksanaan pemicuan dapat menggugah rasa malu masyarakat untuk sadar membangun jamban sehat. Menurut Priatno dkk (2014) bahwa program STBM telah berhasil mengubah pengetahuan dan sikap masyarakat terhadap BABS. Masyarakat yang sudah terpicu akan mendapatkan pengatahuan yang lebih akan pentingnya $B A B$ di jamban. 
Tabel 3. Distribusi Proses Pemantauan dan Evaluasi Program STBM Pilar Stop BABS di Puskesmas Kabupaten Probolinggo Tahun 2015-2016

\begin{tabular}{|c|c|c|c|c|c|c|c|}
\hline \multirow{3}{*}{$\begin{array}{l}\text { Variabel Pemantauan dan } \\
\text { Evaluasi }\end{array}$} & \multicolumn{4}{|c|}{ Pendapat Responden } & \multicolumn{2}{|c|}{ Keadaan Dokumen } & \multirow{3}{*}{ Kategori } \\
\hline & \multicolumn{2}{|c|}{ Melakukan } & \multicolumn{2}{|c|}{ Tidak melakukan } & \multirow{2}{*}{ Ada } & \multirow{2}{*}{ Tidak ada } & \\
\hline & $\mathbf{N}$ & $\%$ & $\mathbf{N}$ & $\%$ & & & \\
\hline $\begin{array}{l}\text { Monitoring perubahan perilaku } \\
\text { BABS masyarakat }\end{array}$ & 10 & $39 \%$ & 16 & $61 \%$ & & $\sqrt{ }$ & Buruk \\
\hline $\begin{array}{l}\text { Evaluasi hasil perubahan perilaku } \\
\text { BABS masyarakat }\end{array}$ & 10 & $39 \%$ & 16 & $61 \%$ & & $\sqrt{ }$ & Buruk \\
\hline $\begin{array}{l}\text { Evaluasi terhadap sasaran } \\
\text { kegiatan pemicuan }\end{array}$ & 10 & $39 \%$ & 16 & $61 \%$ & & $\sqrt{ }$ & Buruk \\
\hline $\begin{array}{l}\text { Evaluasi terhadap target yang } \\
\text { telah dicapai }\end{array}$ & 26 & $100 \%$ & 0 & $0 \%$ & $\sqrt{ }$ & & Baik \\
\hline $\begin{array}{l}\text { Evaluasi pelaksanaan program } \\
\text { STBM Stop BABS dengan } \\
\text { melibatkan masyarakat }\end{array}$ & 14 & $53 \%$ & 12 & $47 \%$ & & $\sqrt{ }$ & Buruk \\
\hline
\end{tabular}

Memang dalam pelaksanaan pemicuan program STBM belum sepenuhnya dapat mengubah perilaku masyarakat secara menyeluruh. Hal ini disebabkan untuk merubah perilaku masyarakat itu membutuhkan waktu yang cukup lama.

\section{Pemantauan dan Evaluasi}

Berdasarkan tabel 3 diketahui bahwa proses pemantauan dan evaluasi program STBM pilar Stop BABS di Puskesmas Kabupaten Probolinggo masih termasuk kategori buruk. Karena petugas sanitasi (61\%) tidak melakukan kegiatan pemantauan perubahan perilaku masyarakat dalam BABS. Selain itu, hanya $53 \%$ petugas sanitasi yang melakukan evaluasi program Stop BABS dengan melibatkan masyarakat. Hal ini dikarenakan petugas sanitasi beranggapan pelaksanaan program STBM hanya sebatas kegiatan pemicuan dan membentuk komite sanitasi tingkat kecamatan. Padahal pemantaun dan evaluasi sangat penting sebagai bahan evaluasi perubahan perilaku masyarakat dalam $B A B$ pasca pelaksanaan pemicuan. Petugas hanya melakukan evaluasi terhadap target yang telah dicapai guna melengkapi laporan data yang akan diserahkan kepada dinas kesehatan

Evaluasi pelaksanaan program STBM Stop BABS dengan melibatkan masyarakat juga tidak sepenuhnya dilakukan oleh petugas sanitasi. Tingkat partisipasi masyarakat yang rendah untuk berdiskusi hasil kegiatan pemicuan juga menjadi masalah tidak berjalannya kegiatan pemantaun dan evaluasi program STBM di Kabupaten Probolinggo.

Menurut Supriyanto dan Damayanti (2007), pemantauan merupakan evaluasi formatif yang dilakukan pada tahap pelaksanaan program dengan tujuan untuk mengubah atau memperbaiki program. Dalam hal ini petugas sanitasi Puskesmas perlu melakukan kegiatan diantaranya: mengecek relevansi dari program dalam hal perubahan kecil yang terus-menerus, mengukur kemajuan terhadap target yang direncanakan, menentukan sebab dan faktor internal maupun eksternal yang mempengaruhi pelaksaaan program. Nike (2015) menyatakan bahwa salah satu faktor yang membuat masyarakat tertarik untuk membangun jamban dan merubah perilaku BABS karena adanya 
Tabel 4. Proses Pencatatan dan Pelaporan, Pendampingan dan Advokasi Program STBM Pilar Stop BABS di Puskesmas Kabupaten Probolinggo Tahun 2015-2016

\begin{tabular}{|c|c|c|c|c|c|c|c|}
\hline \multirow{3}{*}{$\begin{array}{l}\text { Variabel Pencatatan dan } \\
\text { Pelaporan }\end{array}$} & \multicolumn{4}{|c|}{ Pendapat Responden } & \multicolumn{2}{|c|}{ Keadaan Dokumen } & \multirow{3}{*}{ Kategor } \\
\hline & \multicolumn{2}{|c|}{ Melakukan } & \multicolumn{2}{|c|}{ Tidak melakukan } & \multirow[b]{2}{*}{ Ada } & \multirow{2}{*}{ Tidak ada } & \\
\hline & $\mathbf{N}$ & $\%$ & $\mathbf{N}$ & $\%$ & & & \\
\hline $\begin{array}{l}\text { Petugas Sanitasi melakukan } \\
\text { pencatatan dan pelaporan hasil } \\
\text { kegiatan pemicuan }\end{array}$ & 26 & $100 \%$ & 0 & $0 \%$ & $\sqrt{ }$ & & Baik \\
\hline $\begin{array}{l}\text { Petugas sanitasi melakukan } \\
\text { pendampingan program STBM } \\
\text { (Stop BABS) pasca pemicuan }\end{array}$ & 8 & $31 \%$ & 18 & $70 \%$ & & $\sqrt{ }$ & Buruk \\
\hline $\begin{array}{l}\text { Petugas sanitasi melakukan } \\
\text { advokasi kepada pemerintah baik } \\
\text { lintas sektoral dan lintas program } \\
\text { pasca pemicuan }\end{array}$ & 17 & $65 \%$ & 9 & $35 \%$ & & $\sqrt{ }$ & Buruk \\
\hline
\end{tabular}

\section{Pencatatan dan Pelaporan}

Berdasarkan tabel 4 dapat diketahui bahwa Kegiatan pencatatan dan pelaporan hasil pemicuan program STBM pilar Stop BABS sudah masuk dalam kategori yang baik. Karena petugas sanitasi Puskesmas (100\%) telah melakukan kegiatan pencatatan dan pelaporan hasil kegiatan pemicuan. Disamping itu juga terdapat dokumen hasil kegiatan pemicuan juga di tiap Puskesmas. Dalam pelaksanaanya, petugas sanitasi melakukan pelaporan hasil pemicuan kepada Ditjen PP dan PL dalam bentuk format sms. Kemudian laporan hasil kegiatan pemicuan juga digunakan untuk mendata persentase jumlah penduduk yang telah mengakses jamban sehat sebagai sebagai bahan laporan dan evaluasi pencapaian target program STBM kepada dinas kesehatan

\section{Pendampingan}

Kegiatan pendampingan program STBM pilar Stop BABS di Puskesmas Kabupaten Probolinggo masih tergolong kategori yang buruk. Hal ini dikarenakan, petugas sanitasi $(72 \%)$ tidak melakukan pendampingan kepada masyarakat pasca kegiatan pemicuan. Padahal Permenkes RI Nomor 3 Tahun 2014 tentang STBM menerangkan bahwa kegiatan pendampingan perlu dilakukan oleh tenaga kesehatan, kader atau relawan dalam pasca kegiatan pemicuan. Tujuan dari pendampingan program ini untuk mendorong masyarakat agar terus terpicu dan sadar akan pentingnya BAB di jamban sehat.

Globila (2015) menyatakan bahwa kegiatan pendampingan yang cukup dapat meningkatkan pengetahuan masyarakat pasca kegiatan pemicuan. Karena untuk meningkatkan kesadaran masyarakat sangat diperlukan pendampingan yang intensif agar masyarakat mampu tergerak dan mau membangun atau mengkases jamban sehat baik secara pribadi maupun komunal dengan warga lainnya. Menurut Pane (2009) kegiatan pendampingan program yang kurang baik pasca pemicuan dapat berisiko 12,7 kali bagi seseorang untuk BABS kembali. Sehingga dapat disimpulkan bahwa kegiatan pendampingan kepada masyarakat begitu penting dilakukan oleh petugas sanitasi Puskesmas untuk merubah perilaku BABS masyarakat. Apabila proses pendampingan ini 
dilakukan secara berkala oleh petugas, tidak menutup kemungkinan bahwa orang yang telah terpicu akan segera merubah perilaku BAB di jamban sehat.

\section{Advokasi}

Tujuan dari kegiatan advokasi adalah diperolehnya komitmen dan dukungan dari kepala Puskesmas kepada Pemerintah setempat untuk mengupayakan kerjasama baik berupa kebijakan, tenaga, dana, saran, dan keikutsertaan dalam kegiatan pemicuan program STBM Pilar Stop BABS. Dari tabel 4 dapat diketahui bahwa kegiatan advokasi program STBM pilar stop BABS di Puskesmas Kabupaten Probolinggo masih tergolong kategori yang buruk. Karena hanya $58 \%$ petugas sanitasi yang melakukan kegiatan advokasi pasca pemicuan. Padahal kegiatan advokasi adalah hal sangat penting guna mendukung tercapainya target dan pembangunan jamban sehat untuk masyarakat.

Dalam pelaksanaannya, kegiatan advokasi yang telah dilakukan oleh petugas sanitasi dilakukan dengan cara bermitra kepada perusahaan swasta seperti Bank dan Koperasi serta kepada Kepala Desa melalui dukungan berupa dana dari anggaran dana desa (ADD) untuk sanitasi masyarakat. Menurut Globila (2015) kegiatan advokasi kepada pemerintah perlu dilakukan untuk mengembangkan komitmen bersama dalam pembangunan sanitasi desa. Oleh karena itu, penting bagi petugas sanitasi Puskesmas untuk meminta komitmen kepala desa agar mau merencanakan dan memberikan anggaran dana secara khusus untuk pembangunan fasilitas BAB masyarakat berupa jamban sehat. Sehingga, apalagi hal ini berhasil tidak menutup kemungkinan capaian target akses sanitasi jamban sehat akan meningkat tiap tahunnya.

Hasil Capaian dan Faktor Penghambat Program STBM Pilar Stop BABS di Puskesmas Kabupaten Probolinggo

Berdasarkan hasil penelitian, faktor yang menjadi penghambat program STBM pilar stop BABS di Puskesmas Kabupaten Probolinggo adalah dana untuk pembangunan fisik jamban sehat serta faktor sosial-budaya masyarakat. Meskipun kegiatan pemicuan telah dilakukan terus menerus, namun masyarakat masih susah untuk diajak BAB di jamban. Apalagi dana pembangunan jamban sehat tidak ada bantuan khusus dari pemerintah, sehingga untuk mencapai target akses sanitasi jamban sehat masih belum optimal. Alternatif upaya untuk mendorong tercapainya target tersebut, maka petugas sanitasi Puskesmas perlu secara terusmenerus melakukan kerjasama dengan lintas sektor dan lintas program. Sehingga, adanya kerjasama yang baik dapat membantu masyarakat untuk dibuatkan jamban sehat sebagai kebutuhan sanitasi yang layak. Hal tersebut tentunya dapat diperoleh dari bantuan dana dari perusahaan swasta seperti bank koperasi desa dan IUWASH yang merupakan lintas program pemerintah untuk percepatan sanitasi pedesaan.

Disamping itu, faktor sosial budaya masyarakat juga merupakan salah satu faktor penting yang menjadi penyebab tidak tercapainya akses sanitasi jamban sehat di Puskesmas Kabupaten Probolinggo. Hal ini dikarenakan kebiasaan atau tradisi masyarakat yang turunmenurun lebih memilih/menyukai $B A B$ di sungai daripada di jamban. Alasan masyarakat memilih 
sungai karena jarak antara rumah dengan sungai yang relatif dekat. Menurut Chandra (2007), faktor yang mendorong kegiatan pembuangan tinja secara sembarangan antara lain: tingkat sosial ekonomi yang rendah, pengetahuan kesehatan lingkungan yang kurang dan kebiasaan buruk dalam BABS yang diturunkan dari generasi ke generasi. Lingkungan fisik seringkali berkaitan dengan adanya supply air. Mukherjee \& Josodipoero (2000) menyatakan bahwa rumah tangga yang terletak jauh dari fasilitas sumber air, biasanya enggan untuk membangun jamban. Karena air merupakan kebutuhan sanitasi dasar atau hal pokok dalam membangun jamban karena masyarakat lebih menyukai jamban dengan jenis septik tank.

Berdasarkan hasil penelitian, jumlah persentase penduduk yang telah mengakses jamban sehat di Kabupaten Probolinggo masih $60 \%$ pada tahun 2015. Artinya, persentase tersebut belum mampu mencapai target RPJMN terkait akses sanitasi jamban sehat tahun 2010-2014 yaitu sebesar 75\%. Apabila Puskesmas ingin mencapai akses sanitasi jamban sehat maka perlu adanya usaha lebih dalam meningkatkan kegiatan pemicuan program, pendampingan, pemantauan dan advokasi yang dilakukan secara terus menerus. Selain itu, petugas sanitasi juga perlu mengupayakan kerjasama dengan pemerintah baik tingkat desa maupun kecamatan agar terciptanya komitmen baik Kepala Desa maupun pimpinan kecamatan untuk mendukung secara aktif progam STBM pilar Stop BABS. Kegiatan pendampingan dan evaluasi program yang belum dilakukan, sangat penting dilaksanakan oleh petugas sanitasi Puskesmas guna meningkatkan target di tahun berikutnya. Setelah proses perencanaan sampai kegiatan pendampingan dilaksanakan, selanjutnya perlu adanya tim verifikasi STBM tingkat kecamatan untuk melakukan pendataan terkait capain akses sanitasi jamban sehat di Puskesmas Kabupaten Probolinggo.

\section{SIMPULAN}

Hasil evaluasi proses pelaksanaan program STBM pilar Stop BABS di Puskesmas Kabupaten Probolinggo masih tergolong kategori buruk. Hasil kateogri tersebut disebabkan oleh faktor perencanaan program STBM yang tidak dilakukan oleh petugas sanitasi Puskesmas antara lain analisis situasi dan identifikasi masalah, pembentukan fasilitator STBM tingkat desa dan pembentukan forum/kelembagaan diskusi sanitasi masyarakat. Selain itu, kegiatan pendampingan dan advokasi masih dalam kategori buruk karena tidak sepenuhnya petugas sanitasi Puskesmas yang melakukan. Namun, pelaksanaan dan pencatatan pelaporan hasil pemicuan program STBM sudah sudah dilakukan oleh petugas sanitasi Puskesmas sehingga masuk dalam kategori yang baik.

Saran yang dapat direkomendasikan kepada Petugas sanitasi Puskesmas di Kabupaten Probolinggo adalah perlu membentuk fasilitator STBM tingkat desa untuk mengoptimalkan proses pemantauan evaluasi sasaran dan pendampingan kepada masyarakat. Selain itu, memperkuat kerjasama dengan masyarakat, lintas sektor dan lintas program penting dilakukan guna mendukung keberhasilan program STBM pilar Stop BABS. Untuk penelitian selanjutnya dapat dilakukan uji pengaruh 
untuk mengetahui faktor yang mempengaruhi

ketidakberhasilan program STBM pilar Stop BABS.

\section{DAFTAR PUSTAKA}

Balitbang Kemenkes RI. 2013. Riset Kesehatan Dasar. RISKESDAS. Jakarta: Balitbang Kemenkes RI

Bryan, Carolie dan Louis G. White., 1987. Manajemen Pembangunan Untuk Negara Berkembang. LP3ES. Jakarta

Chandra, B, 2007. Pengantar kesehatan lingkungan. Penerbit buku kedokteran EGC. Jakarta

DirektoratPenyehatanLingkungan. STBM Sanitasi Total BerbasisMasyarakat.htpp://stbmindonesia.org/. [Diaksestanggal 10 desember 2015]

DinasKesehatanKabupatenProbolinggo. 2015. Data Baseline dan Monev STBM Kabupaten Probolinggo. http://stbm-indonesia.org, diaksestanggal 10 desember 2015

Globila, N. 2015. Evaluasi program Sanitasi Total Berbasis Masyakat Menuju Desa ODF di kelurahan Dawuhan Kecamatan Dawuhan Kabupaten Situbondo. [Skripsi]. FKM UNAIR. Diakses tanggal 5 Mei 2016 di http://fulltext.lib.unair.ac.id.

Kar, K and R. Chambers. 2008. Handbook on Community-Led total Sanitation. Plan UK. London

Kementerian Kesehatan RI. 2014. Permenkes RI No. 3 Tahun 2014 tentang Sanitasi Total Berbasis Masyarakat. Jakarta

Mukherjee, N dan Josodipoero, R.I. 2000. "Menjual jamban?” Bukan, Menjual Gaya hidup. Disitasi pada tanggal 14 mei 2016 Http://www.waspola.org/file/pdf/publications/stu dy_isitselling_ind.pdf.
Nike, Frans. 2015. Menuju Pembangunan Sanitasi Berkelanjutan: Pembelajaran dari Program STBM di Provinsi Nusa Tenggara Timur. IRGSC Policy Brief. No. 13 Februari 2015. Diakses pada tanggal 10 Mei 2016 di www.irgsc.org

Pane E. 2009. Pengaruh Perilaku Keluarga Terhadap Penggunaan Jamban. Jurnal kesehatan Masyarakat Nasional. Hal. 229

Priatno T, Zauhar S, Hanafi I. 2014. Faktor-faktor yang berpengaruh terhadap keberhasilan Program Sanitasi Total Berbasis Masyarakat (STBM) di Kota Tasikmalaya. [Jurnal Kesehatan Komunitas Indonesia]. (Diakses pada 7 April 2015). Dapat diunduh di : http://lppm.unsil.ac.id/files/2015/02/06.-Teguhpriatno.pdf

Solikhah S. 2012. Hubungan pelaksanaan Program ODF (Open Defecation Free) dengan perubahan perilaku masyarakat dalam Buang Air Besar di luar jamban di Desa Kemiri Kecamatan Malo Kabupaten Bojonegoro. [Jurnal]. (Diakses pada 9 April 2015). Dapat diunduh di : http://stikesmuhla.ac.id/wpcontent/uploads/jurnalsurya/noXVIII/84-90Jurnal-Siti.pdf

Stufflebeam, Daniel L. \& Shinkfield, Antony J. (2007). Evaluation Theory, Models, and Application, San Fransisco: Jossey-Bass.

Supriyanto, S, Damayanti, NA. 2007. PerencanaandanEvaluasi. Airlangga University Press. Surabaya

Terry, George R. Dan Rue, Leslie W. 2005. Dasardasar manajemen. Jakarta: Bumi Aksara

Trihono, 2005. Manajemen Puskesmas Berbasis Paradigma Sehat. Jakarta: CV Sagung Seto

Zastrow, Charles. 2008. Introducion to Social Work and Socia Welfare. Empowering People. Thomson Peolpe. Thomson Books, BelmontUS. 